\title{
Na escola, o artesanato
}

At school, the handicraft

\begin{abstract}
Resumo
Porque o artesanato representa uma das pedras basilares da cultura dos povos e dada a importância que este representa para o enriquecimento e historicidade de cada individuo, comunidade e país, foi realizado o estudo com o intuito de verificar: De que forma o sistema de ensino português incentiva a promoção e valorização do patrimônio artístico nacional; que importância é dada à aquisição de competências especificas no saber-fazer, como resposta às necessidades especificas do país e dos jovens estudantes; e por fim, analisar de que forma a aliança entre o ensino das artes visuais e o estudo das técnicas, estéticas e saberes artesanais pode contribuir para a formaçao e preparação dos jovens no ingresso na vida ativa. Debruçando-me especificamente sobre a prática artesanal, foi indispensável então verificar de que forma o artesanato se ajusta à passagem do tempo e à mudança e se o artesanato tem atualmente a capacidade de se assumir como uma atividade profissional viável aos jovens criadores, após o término do ensino secundário.
\end{abstract}

Palavras-chave: Educação, sociedade, saber-fazer, patrimônio cultural, artesanato contemporâneo

\begin{abstract}
Because handicraft is one of the cornerstones of peoples' culture and given the importance that it represents for the enrichment and historicity of each individual, community and country, the study was conducted in order to verify: How the Portuguese education system encourages the promotion and valuation of the national artistic patrimony; what importance is given to the acquisition of specific skills in the know-how, as a response to the specific needs of the country and young students, and finally, analyze how the alliance between visual arts teaching and the study of techniques, aesthetics and craft knowledge can contribute to the formation and preparation of young people in the labor market entrance. Addressing specifically to the handicraft practice, it was essential to check how handicraft adapts to the passage of time and change, and if the handicraft currently has the ability to assume a viable occupation for young creators, after the end of secondary school.
\end{abstract}

Keywords: Education, society, know-how, patrimonial heritage, contemporary handicraft

\section{Na escola, a formação e a sociedade}

De que forma o sistema educativo se adequa ou se move relativamente às necessidades evidenciadas, em constante evolução e transformação, que é a sociedade onde está inserido? (VIEIRA \& VIEIRA, 2004).

O ensino do saber-fazer, a passagem do saber cultural e técnico e a capacitação para actividades específicas a exercer num determinado grupo social, há muito que marcam presença na nossa história enquanto Humanidade (PINTO, A.; MEIRELES, F. ; CAMBOTAS, M., 2001). Partindo desta acepção e debruçando-me sobre a Lei de Bases do 
Sistema Educativo Português (LBSE, Dec. Lei no 49/2005 de 30 de Agosto), verifico que educação, formação e sociedade surgem como conceitos parceiros quando nos remetemos para os princípios fundamentais do sistema educativo. Corroborando a importância e a correlação entre estes fatores, Desbordes (1977) refere que não há sociedade sem educação e que a escola tem o papel de contribuir para o progresso da sociedade, formando os Homens de forma a satisfazer as necessidades desta. Assim, considerando que uma qualquer sociedade organizada não pode existir sem educação, podemos sintetizar educação como o ato de educar, ensinar, instruir, formar os sujeitos, de forma a lhes permitir agir e actuar em conformidade com as regras, expectativas e necessidades - econômicas, técnicas, culturais e morais - ditadas pela sociedade em que estão inseridos (BECK, s.d.; DESBORDES, 1977; MARANGE, 1977).

"Tal sociedade, tal escola" (DESBORDES, 1977, p.21). Desta afirmação, podemos retirar duas ideias: a escola é um reflexo da sociedade onde está inserida e a escola apresentase, como reflexo da dita sociedade, permeável à mudança e à adaptação, acompanhando o evoluir do seu contexto social (DESBORDES,1977; MARANGE,1977; SÉGUY, 1977). Da escola é esperado que de uma forma atual e realista, capacite formativa, intelectual, cultural e moralmente os indivíduos, para a persecução dos valores e para o colmatar das necessidades específicas da sociedade a que pertencem (DESBORDES, 1977; MARANGE,1977). Como preconiza a LBSE (Dec. Lei no 49/2005 de 30 de Agosto), esta deverá assegurar, além do desenvolvimento equilibrado da personalidade dos alunos, a aquisição de ferramentas e meios que facilitem a estes um justo ingresso na vida activa, possibilitando que se tornem agentes conscientes, críticos, úteis e activos para o progresso da sociedade (DESBORDES, 1977; MARANGE, 1977).

\section{O saber-fazer e o patrimônio artístico cultural no Sistema de Ensino Português}

O ensino do saber-fazer, de caráter técnico e profissionalizante, há muito que marca presença nas políticas educativas do país. Entre 1794 e 1837 (segundo R. A. AZEVEDO, 1972, in FERNANDES, GOMES e GRÁCIO, 1988), várias tentativas foram feitas no sentido de implementar um sistema educativo que abrigasse o ensino agrícola, industrial e politécnico. Já em 1875, é interessante verificar que, segundo Fernandes (et al. 1988), a evolução do ensino técnico e profissional esteve sujeita às movimentações e transformações sentidas no campo econômico, tão atual como na sociedade dos nossos dias (MADEIRA, 2006). No período pós-guerra, na década de 1950, a elevada taxa de analfabetismo e a escassez de técnicos e de mão-de-obra qualificada alertaram os dirigentes educativos nacionais para a necessidade de fomentar a formação profissional, aliados que estavam estes fatores com os problemas econômicos e de desenvolvimento 
do país (Organización de Estados Iberoamericanos para la Educación la Ciencia y la Cultura [OEI], 2003). Com a chegada da democracia muitas foram as mudanças estruturais e organizacionais realizadas, que alteraram para sempre os fundamentos do sistema educativo Português. Dessas, resultaram em 1986 as medidas que viriam a constituir a Lei de Bases do Sistema Educativo (OEI, 2003). Entre elas é de destacar a medida de alteração estrutural enunciada para o ensino secundário, criada em 1983, que justifica a criação dos cursos técnico-profissionais e específica a dupla valência das suas características: "a necessidade de mão-de-obra qualificada e a prossecução de uma política de emprego para os jovens leva à criação de cursos técnico-profissionais, (...) que permitem o acesso ao ensino superior, e diplomas de formação técnico-profissional para ingresso no mundo do trabalho" (OEI, 2003, pp. 24,25).

Lançando um olhar sobre a actual LBSE (Dec. Lei no 49/2005 de 30 de Agosto), procurando realçar a importância dada pelo sistema educativo ao ensino do saber-fazer e ao ensino para a valorização do patrimônio cultural português, começo por citar que "o sistema educativo responde às necessidades resultantes da realidade social, contribuindo para o desenvolvimento pleno e harmonioso da personalidade dos indivíduos, incentivando a formação de cidadãos livres, responsáveis, autônomos e solidários e valorizando a dimensão humana do trabalho". Segundo o mesmo documento, dos indivíduos é esperado o empenho na transformação progressiva da sociedade, atuando sobre o meio social de forma crítica e criativa, depois de adquiridas as bases formativas que the proporcionem um justo lugar na vida ativa. No mesmo sentido, na escola, o ensino do saber fazer, a teoria e a prática devem aliar-se aos conhecimentos que permitam o prosseguimento de estudos ou a inserção do aluno em esquemas de formação profissional. Em ambas as componentes, a formação de caráter técnico, tecnológico e profissionalizante é privilegiada, com o objetivo de facilitar o ingresso do aluno na vida ativa ou no mundo do trabalho, em atividades ajustadas aos seus interesses, capacidades e vocação. Relativamente à gestão do currículo de ensino, Eisner e Vallance (1974, in PACHECO, 2001, p.33) defendem que este deve ser construído centrado no aluno, tendo em conta o "como se aprende e não propriamente o quê". Deve incentivar a autonomia e desenvolvimento pessoal e social e possibilitar o uso inteligente e prático dos conteúdos escolares, transformando-os no que Roldão (2003) denomina de saber em uso em oposição ao chamado saber inerte - saberes com os quais o aluno não se sabe agir ou utilizar em qualquer operação ou situação. Segundo a mesma autora é importante a implantação de práticas que capacitem o aluno para uma efetiva capacidade de usar, aplicar ou agilizar adequadamente os conteúdos ou conhecimentos adquiridos na escola, nos vários domínios ou parâmetros da sua vida futura. Assim, o 
ensino deveria focar-se no equilíbrio entre aquilo que o aluno aprende, com aquilo "vai precisar, pessoal e socialmente, para uma boa integração social", aproximando-se desta forma a escola e o ensino do que é a sua função social primordial, a de garantir que as aprendizagens são adquiridas e os conhecimentos utilizáveis em termos práticos, na vida social, pessoal e profissional dos alunos (ROLDÃO, 2003, p.17). Por outro lado, é um requisito do sistema educativo que o ensino "contribua para a defesa da identidade nacional e para o reforço da fidelidade à matriz histórica de Portugal, através da consciencialização relativamente ao patrimônio cultural do povo português" e que propicie o desenvolvimento de conhecimentos e o "apreço pelos valores característicos da identidade, língua, história e cultura portuguesas" (LBSE, Dec. Lei no 49/2005 de 30 de Agosto).

Por fim, o sistema de ensino tem como objetivo "formar, a partir da realidade concreta da vida regional e nacional, e no apreço pelos valores permanentes da sociedade em geral, e da cultura portuguesa em particular, jovens interessados na resolução dos problemas do País" (LBSE, Dec. Lei no 49/2005 de 30 de Agosto). Para isso, como refere Teodoro (1982), após o ensino básico os caminhos escolares deverão admitir uma diversidade de vias que os alunos poderão optar por ingressar, traçadas de acordo com as necessidades do País e o seu previsível desenvolvimento, tornando-se bastante óbvia a relação existente entre educação/economia e educação/mercado de trabalho (MADEIRA, 2006).

Neste sentido e segundo Castro (1999), o artesanato poderá surgir como um potenciador de emprego e desenvolvimento regional, uma vez que encerra em si a capacidade de se adaptar às novas realidades e respectivas necessidades de mercado. Segundo o mesmo autor, o artesanato pode ainda contribuir como incentivo ao progresso e desenvolvimento do país e como meio de inserção dos jovens indivíduos na sociedade e no mercado de trabalho. Efetivamente e segundo o mesmo autor, o artesanato é um veículo rico em aprendizagem sobre as raízes, sobre a identidade e a cultura nacional de cada nação, sendo por isso de valorizar a exploração desta temática artística em contexto escolar.

\section{Um percurso pelo Artesanato}

"A cidade sufoca-o". É desta forma que Delahaye (2000, p.10) define o interesse crescente, por parte da população citadina, que atualmente se tem verificado pela atividade artesanal - o artesanato e o artesão. O artesanato caracteriza-se como uma actividade de invenção e produção de artefatos, realizados pelo Homem, com vista a 
satisfazer, a dada altura, as necessidades específicas, utilitárias e estéticas, da sociedade ou do grupo em que se insere. Fazendo um olhar retrospectivo pelas etapas de evolução da Humanidade, vemos que este representou uma das primeiras formas de expressão identitária da cultura dos diversos povos, nas diferentes sociedades e épocas da história (CASTRO, 1999; SANTOS, 1998). Desde a civilização Neolítica de 6000 a.C. que o Homem moldou os seus hábitos e práticas, adquirindo faculdades que the permitiram desenvolver atividades artesanais como fiação, tecelagem, cestaria e cerâmica (PINTO, A. et al, 2001). Muitas vezes objetos e produtos, nomeadamente os de cerâmica, possuíram um papel privilegiado no seio daquela sociedade. No entanto, nem sempre o artesanato existiu como um produto reconhecido, de afirmação de um patrimônio cultural específico. Nem o seu criador artesão possuiu um estatuto social e cultural, considerado de importância e relevo para a história e identidade da sociedade em que se viu inserido (ANTUNES, 2000). O estatuto do artesão e o papel cultural e social das suas criações apresentou-se oscilante ao longo dos séculos. Ora escravo sem reconhecimento, ora livre e ambulante, sendo os produtos por ele criados considerados ora de "objetos imperfeitos, com uma fraca qualidade dos seus materiais", ora como "peça artística de reconhecido valor estético" (ANTUNES, 2000, p.15; CASTANHO, 2000; CASTRO, 1999, p.18).

Segundo Castro (1999), a evolução do artesanato sofreu um revés quando da revolução industrial. Progressivamente foi sendo rotulado como uma atividade menor (ou arte menor segundo Antunes, 1999), num tempo onde a produção em massa e a má qualidade artística e estética dos produtos baratos impera, dominada por comerciantes e imitadores que mais não fazem que oferecer "produtos feios só porque se vendem" (DELAHAYE, 2000, p.11).

Procurando então definir artesanato, e partindo da sua acepção mais generalista, artesanato representa "toda a atividade produtiva de objetos e artefatos, realizados manualmente ou com a utilização de meios rudimentares ou tradicionais" pouco difundidos (NETO, s.d., p.3). A intervenção da ação do homem é denotada em todas as fases do processo de trabalho, desde a produção à venda, sendo esta feita por vezes na sua própria casa ou oficina. Muitas vezes, do sucesso deste processo, depende o sustento da família (ANTUNES, 2000; CASTRO, 1999; NETO, s.d.; SANTOS, 1998). O artesanato, produto do gênio criativo do artesão, é e está estritamente ligado e influenciado pela cultura, região e pelos recursos naturais em que está inserido. E tem a capacidade de, segundo Castro (1999, pp.11-12), caracterizar e definir "a identidade de um povo" como forma da expressão mais genuína e autêntica das suas tradições, usos e costumes. É realizado individualmente ou com um reduzido número de artesãos, na forma de pequena empresa que, não raras vezes, é formada por grupos familiares onde o ofício do saber-fazer artesanal passou de geração em geração e onde a formação escolar é, de 
maneira geral, baixa (CASTRO, 1999). Reproduções do modelo original ou exclusivas e originais, essas peças, utilitárias ou artísticas, são normalmente produzidas em pequena série, denotando-se nelas a "habilidade, destreza, apuro técnico, engenho e arte" do seu criador, recebendo por isso o apreço e valor como patrimônio cultural (CASTRO, 1999; NETO, s.d., p. 3). Ao artesão detentor do saber-fazer, além das referências já descritas, cabe o papel de, direta ou indiretamente, perpetuar a sua atividade artesanal. Quer pela formação de novos artesãos - o mestre-artesão. Quer pela própria manutenção ou perpetuação da atividade, quando recorre a práticas e saberes tradicionais, conjugados com saberes técnicos relativos aos materiais, à destreza manual, ao sentido estético e ao conhecimento e aplicação dos elementos estilísticos da comunidade onde se insere (ANTUNES, 1999; CASTRO, 1999; NETO, s.d.). Uma dúvida que surge normalmente quando se debate sobre a atividade do artesão ou o fazer artesanal, é a legitimidade do uso de ferramentas de trabalho, sendo que atividade artesanal pressupõe a produção de objetos manufaturados onde se subentende um processo de "fazer/produzir à mão, de modo caseiro, artesanal" (Guedes [Dir.] Dicionário de Língua Portuguesa). O Estatuto do Artesão (Dec. Lei n.o 41/2001, de 9 de Fevereiro) contempla o recurso a "equipamentos de produção" quando estes visem o "diminuir a penosidade do processo produtivo ou a rentabilizar a produção desde que, em qualquer caso, seja salvaguardada a natureza e qualidade do produto ou serviço final". Segundo Santos (1998), toda a atividade produtiva artesanal pressupõe o uso de mecanismos de força, sejam naturais, como a força do próprio corpo, ou artificiais, como as ferramentas de trabalho rudimentares. As mãos e a destreza do artesão são as suas principais ferramentas, são elas que definem o processo e a cadência da criação (LIMA, s.d.; NETO, s.d.). No entanto para trabalhar os materiais e para deles fazer surgir as mais variadas formas e detalhes, necessita do auxílio de utensílios que funcionam como uma extensão do seu corpo, trabalhando em função e sob o comando deste, fazendo estas ferramentas parte da identidade dos próprios objetos criados (ANTUNES, 1999; LIMA, s.d.; SANTOS, 1998).

\section{Para o artesanato, que caminho?}

Segundo Antunes (2000) e Castro (1999), se sente o risco de, por um lado, ao se verem envelhecer e desaparecer os artesãos, se ver desaparecer também a essência do ofício. Constata-se, por outro lado, o progressivo aumento da procura comercial destes produtos.

O rejuvenescido interesse na redescoberta do artesanato poderá dever-se porventura ao saudosismo associado a estas peças, como expressão nostálgica de uma persistência do passado, associado ao seu reconhecido valor social e cultural, econômico e afetivo 
(ANTUNES, 1999; CASTRO, 1999; PERDIGÃO, 2001). Perdigão (2001, Introdução) acrescenta ainda que o interesse por estas peças singulares, autênticas e exóticas, residem no fato de se encontrarem e, para além disso, incorporarem a expressão de um passado que vincula o comprador, permitindo-Ihe uma renovação da sua identidade. Deste modo, sublinha-se que a valorização afetiva de um objeto reside, portanto, na forte carga identitária que cada indivíduo Ihe atribui, a que se junta que esse objeto tem de evocar e trazer consigo duplamente a memória de um povo e a memória afetiva.

No entanto o interesse das camadas mais jovens pela aprendizagem do ofício é pouco notada, como defende Castro (1999), consequência das duras condições de trabalho que grande parte das actividades artesanais oferece e pela ambição revelada pelos jovens na procura de melhores condições de trabalho, que proporcionem uma maior estabilidade e rendimento fixo.

O artesanato, tido como elemento integrante e expressivo da cultura histórica e regional, não se pode alienar ao constante dinamismo e mudança de sentidos na sociedade em que está inserido, sob a pena de não acompanhar a sua evolução e a evolução do ciclo económico da procura e das necessidades do mercado.

Com o arrancar da produção em massa, aliada aos novos métodos de fabrico mecânicos e industriais e às novas demandas dos mercados, previu-se, em finais do século XIX, o esquecimento e extinção da atividade artesanal, tendo-se o artesanato deparado com uma fase sensível de decadência e marginalização econômica e social (ANTUNES, 2000; CASTRO, 1999; NETO, s.d.). No entanto, e lançando um olhar sobre as culturas do passado e da atualidade, denotamos no artesanato um denominador comum e persistente, revelando este uma capacidade de adaptação e atualização constante, acompanhando os gostos, mudanças e evoluções culturais, econômicas, sociais e politicas relativamente à sociedade em que está inserido (LIMA, s.d.; SANTOS, 1998; PERDIGÃO, 2001; ANTUNES, 2000).

O ressurgimento da procura e o gosto pelo artesanal fizeram pulsar o setor, e sendo a atividade artesanal aberta à inovação, esta acompanhou o evoluir dos padrões de produção e de consumo, permeabilizando e flexibilizando os usos e funções dos objetos tradicionais, passando estes de objetos utilitários a decorativos e vice-versa. Vejam-se os casos de peças utilitárias de barro, infusas ou alguidares de amassar, agora convertidas a peças rústicas de decoração. Permitiu a adoção de novos materiais, quer matéria-prima provenientes de outras regiões, por razões ecológicas, quer materiais de produção 
industrial ou química. Permitiu ainda a adoção de novas técnicas e desenhos, adquirindo uma nova identidade, sem perder no entanto as características próprias da sua região ou as particularidades dos saberes tradicionais, conservando, acima de tudo, a sua originalidade e autenticidade (ANTUNES, 1999; CASTRO, 1999; HENRIQUES, 2000;PERDIGÃO, 2001; SANTOS, 1998).

Amanhã, o artesão continuará a existir, adaptando-se e adaptando os seus artefatos às mudanças ecológicas, sociais, históricas e culturais para que, depois de amanhã, existam testemunhos de civilizações e culturas, tal como até nós, hoje, nos chegam testemunhos das civilizações de antes de antes de ontem (CASTANHO, 2000, p.23).

\section{Na escola, o Artesanato - uma estratégia de salvaguarda e preservação}

Se "é possível, hoje em dia, reconhecer o valor econômico e cultural inestimável que é o artesanato dentro das suas especificidades regionais" (CASTRO, 1999, p.18), este ainda carece, quiçá, de ser colocado no seu lugar! No bom sentido é claro.

A divulgação da cultura e práticas artesanais deverá constituir-se como uma preocupação de primeira linha, possibilitando a perenidade desta arte e afugentando o progressivo esquecimento dos seus saberes, das suas técnicas e das suas expressões.

Segundo a Convenção para a Salvaguarda do Patrimônio Cultural Imaterial da UNESCO (2003) existe já uma vontade universal e uma preocupação comum, de salvaguardar o património cultural imaterial da humanidade. Como é preconizado pela Convenção (UNESCO, 2003), sobre o património cultural imaterial (entendido como as "práticas, representações, expressões, conhecimentos e técnicas (...) instrumentos, objetos, artefatos e lugares culturais que lhes são associados - que as comunidades (...) reconhecem como parte integrante do seu patrimônio cultural", e no qual se incluem, entre outros, as "técnicas artesanais tradicionais") deverá recair o investimento das sociedades, promovendo a sua valorização e preservação, consciencializando, especialmente as camadas mais jovens, para a necessidade da sua salvaguarda e proteção, visando conservar a sua presença e possibilitar a continuidade, a transmissão e a "revitalização deste patrimônio nos seus diversos aspectos".

Aos países vinculados pela Convenção e entre os quais esta esteja em vigor é requisitado que procurem garantir a salvaguarda e valorização do patrimônio cultural imaterial presente no seu território, promovendo os meios e as estratégias que garantam da melhor forma a disseminação destas necessidades, particularmente junto dos jovens, 
recorrendo sobretudo a programas educativos, orientados para a valorização e descoberta, da função, da historicidade e da importância que este patrimônio representa para a afirmação e caracterização da nossa identidade nacional (UNESCO, 2003). A escola, representando um veículo privilegiado para a formação e promoção de saberes, assume o papel de, como se sabe, responder às necessidades e preocupações próprias da sociedade onde está inserida (DESBORDES, 1977). Desta forma, a escola e o sistema educativo apresentam-se como uma estrutura base privilegiada para estas aprendizagens, podendo perpetuar a sua divulgação e instigar à sua salvaguarda.

Os currículos de Artes Visuais propõem de fato como princípios e competências essenciais a adquirir pelos alunos, a construção de uma consciência de valorização e preservação do património artístico e cultural português (ME, 2001a; ME, 2001b, ME, 2005). Os programas das disciplinas facilitam também ao professor a flexibilidade suficiente na sua gestão para encorajar a pesquisa, o debate e a descoberta sobre artesanato. As suas origens e temáticas, os seus autores, as características dos materiais e técnicas mais usadas nas diversas expressões. Assim como proporcionar visitas de estudo a oficinas de artesãos e artistas, a feiras de artesanato tradicional e a lojas de artesanato contemporâneo.

Estando hoje perante uma situação cada vez mais alarmante de desemprego jovem ${ }^{1}$, de indivíduos entre os 15 e os 24 anos e citando Charréu (2009, p.27) questiono, "interessará verdadeiramente aos alunos e, por extensão, à sociedade, a educação artística em Artes Visuais que hoje recebem via instituição escolar oficial?"

\section{O artesanato na contemporaneidade}

As aprendizagens adquiridas ao longo da formação escolar do aluno podem proporcionarIhe aptidões, capacidades e ferramentas que lhe garantam oportunidades para um ingresso justo no mundo ativo do mercado de trabalho e as oportunidades poderão passar também pela criação e produção artesanal (CASTRO, 1999). Castro (1999, p. 41) explica que o artesanato poderá ser olhado sob uma "óptica de progresso", consideradas as suas potencialidades para a empregabilidade e para a criação de novos postos de trabalho, em áreas tão variadas como a cultura, o turismo e o ambiente. Refere ainda que esta atividade tem vindo a registar um progressivo aumento da procura, por parte dos jovens, "com vista à criação do próprio emprego" (CASTRO, 1999, p.26).

\footnotetext{
${ }^{1}$ Agência Lusa (2012, 14 de Novembro). Taxa de desemprego jovem no terceiro trimestre quase nos 40 por cento. RTP Noticias. Acedido em http://www.rtp.pt/noticias/
} 
Muitos jovens, os protagonistas do chamado artesanato contemporâneo ou urbano, viram na criação artesanal uma oportunidade de desenvolvimento de uma atividade profissional, autônoma e criativa (CASTRO, 1999). O artesanato contemporâneo ou urbano partilha as raízes do artesanato tradicional. No entanto soube distanciar-se deste pela vivência urbana dos seus criadores, na sua maioria jovens escolarizados, e pelo recurso a novas estéticas, processos e materiais (CASTRO, 1999; ANTUNES, 2000). Por norma, estes artesãos artistas, assim denominados pela larga presença de indivíduos provenientes de círculos sociais criativos ou intelectuais ou com formação escolar artística ou superior e provenientes de áreas urbanas, procuram no artesanato uma fonte de rendimento permanente ou complementar, praticando uma produção em pequena escala, mas que contudo inova, técnica e formalmente, nos produtos que produz (ANTUNES, 2000; CASTRO, 1999; SILVA, 1989). Estes produtos são agora realizados com o propósito de assumirem uma nova leitura, facilitada pela introdução de novas estéticas, materiais, formas e motivos. Potenciados pela introdução de novos métodos, práticas e instrumentos de trabalho, que permitiram alterar a função dos objetos produzidos, transitando muitas vezes do tradicional uso utilitário para o decorativo (ANTUNES, 2000; CASTRO, 1999). O artesanato de recuperação passou também a marcar posição nestas novas práticas artesanais e caracteriza-se pela produção de objetos, recorrendo somente à reutilização ou recuperação de matérias-primas não aproveitadas ou desperdiçadas pelo consumo ou por outras atividades (CASTRO, 1999). Fator comum a toda a heterogeneidade de novos artesãos de artesanato contemporâneo de cariz popular é a preocupação pela manutenção das suas origens pela preservação da essência da tradição artesanal do ofício (CASTRO, 1999; ANTUNES, 2000)

A atividade artesanal não deve assim temer a adoção de novas metodologias, temáticas ou inovações técnicas, desde que seja sempre garantida e dignificada, a sua identidade e originalidade (CASTRO, 1999). Desta forma o artesanato urbano não deixa também de representar (como se tem verificado com o artesanato tradicional) a nossa identidade temporal, na medida em que reflete as "realidades sociais, culturais e econômicas" do contexto e do tempo em que vive (ANTUNES, 2000, p. 15). Para finalizar, e debruçando-me sobre Declaração de Jacarta (WCC / UNESCO, 1985) sobre o papel do artesanato no processo de desenvolvimento, é reforçado que "o artesanato é vital para todos os países em desenvolvimento nas escalas econômica, social e cultural", atuando como um impulsionador de progresso e desenvolvimento (em especial nos países pobres), proporcionando o sustento e subsistência a milhões de pessoas por todo o mundo.

\section{Referências}


Agência Lusa. Taxa de desemprego jovem no terceiro trimestre quase nos 40 por cento. RTP Noticias. 2012, 14 de Novembro. Acedido em http://www.rtp.pt/noticias/index.php?article $=603365 \& \mathrm{tm}=5 \&$ layout $=121 \& \mathrm{visual}=49$

ANTUNES, L. Das Artes e Ofícios Tradicionais: Contributos para o estudo do enquadramento normativo legal. 1999. Versão electrônica do artigo da publicação periódica do Observatório das Atividades culturais, OBS n6. Consult. 10 Dezembro 2011, disponível em http://www.oac.pt/pdfs/OBS_6_Das\%20Artes\%20e\%200f\%C3\%ADcios\%20 Tradicionais ANTUNES, L. Para um cenário das transformações identitárias dos artesãos. In Feira Internacional de Artesanato - FIL. As idades do futuro. Lisboa: IEFP, 2000.

BECK , N. Educar para a vida em sociedade: estudos em ciência da educação. Porto Alegre: Edipucrs. S.d. Consult. 8 Dezembro 2011, disponível em http://books.google.pt/books?id=hIWV3iziLMUC\&printsec $=$ frontcover\&source $=g$ bs g su mmary $r \& c a d=0 \# v=$ onepage $\& q \mathrm{f}=$ false

CASTANHO, H. Artesanato/Ecossistemas (antes de ontem, ontem, hoje, amanhã). 2000 In Feira Internacional de Artesanato - FIL. As idades do futuro. Lisboa: IEFP, 2000.

CASTRO, M. N. Artesanato - Medidas de Apoio numa Perspectiva de Desenvolvimento da Atividade (Reflexões para a Definição de uma Estratégia). Lisboa: Instituto de Emprego e Formação Profissional do Ministério do Trabalho e da Solidariedade, 1999.

CHARRÉU, L. Para uma educação artística em artes visuais focada na contemporaneidade. In RODRIGUES, Edvânia Braz Teixeira; ASSIS, Henrique Lima (Orgs). O Ensino das Artes Visuais: Desafios e possibilidades contemporâneas. Goiânia: Grafset Ed./ Secretaria de Educação do Governo do Estado de Goiás, 2009. pp.39-58.

Decreto-Lei n. ${ }^{4}$ 41/2001, de 9 de Fevereiro. Estatuto do artesão e da unidade produtiva artesanal. Lisboa. Consult. 5 Dezembro de 2011, disponível em http://dre.pt/pdf1sdip/2001/02/034A00/07240727.PDF 
Decreto-Lei no 49/2005 de 30 de Agosto. Lei de Bases do Sistema Educativo. Diário da República-I Série-A. Ministério da Educação. Lisboa. Consult. 10 Janeiro 2012, disponível em http://dre.pt/pdf1sdip/2005/08/166A00/51225138.pdf

DELAHAYE, G. O artesanato: Uma aventura moderna. In Feira Internacional de Artesanato - FIL. As idades do futuro. Lisboa: IEFP, 2000.

DESBORDES, L. Um universo não fechado. In Niza, S. (Dir.). A escola e a sociedade. Lisboa: Editorial Estampa, 1977.

FERNANDES, R., GOMES, J. e GRÁCIO, R. História de educação em Portugal. Lisboa: Livros Horizonte, 1998.

GUEDES, F. (Dir.). Dicionário de Língua Portuguesa 2a ed. Lisboa: Verbo, 2008.

HENRIQUES, R. P. Objectos com raízes. In Feira Internacional de Artesanato - FIL. As idades do futuro. Lisboa: IEFP, 2000.

LIMA, R. Artesanato e arte popular: duas faces de uma mesma moeda? S.d. Consult. 10 Janeiro 2012, disponível em http://www.cnfcp.gov.br/pdf/Artesanato/Artesanato_e_Arte_Pop/CNFCP_Artesanato_Art e_Popular_Gomes_Lima.pdf

MADEIRA, M. H. Ensino Profissional de Jovens: Um Percurso Escolar Diferente para a (Re)Construção de Projectos de Vida. Rev. Lusófona de Educação. [online]. (2006), no.7 [citado 25 Janeiro 2012], p.121-141. Disponível na World Wide Web: <http://www.scielo.oces.mctes.pt/scielo.php?script=sci_arttext\&pid=S1645$72502006000100008 \&$ lng $=$ pt\&nrm=iso $>$. ISSN $1645-7250$.

MARANGE, J. Pôr cada um em condições de ser senhor do seu destino. In Niza, S. (Dir.) A escola e a sociedade. Lisboa: Editorial Estampa, 1977.

Ministério da Educação. Currículo Nacional do Ensino Básico. Competências Essenciais. Lisboa. Departamento da Educação Básica. 2001a. Consult. 22 Setembro 2011, disponível em http://www.dgidc.min-edu.pt

Ministério da Educação. Programa de Desenho A $10^{\circ}$ ano. Lisboa. Departamento do Ensino Secundário. 2001 b. Consult. 22 de Setembro 2011, disponível em http://www.dgidc.min-edu.pt 
Ministério da Educação. Programa de Oficina de Artes $12^{\circ}$ ano. Lisboa. Departamento do Ensino Secundário. 2005. Consult. 22 de Setembro 2011, disponível em http://www.dgidc.min-edu.pt

NETO, E. O que é o artesanato. S.d. Consult. 8 Dezembro 2011, disponível em http://www.fbes.org.br/index.php?option=com_docman\&task=doc_download\&Itemid=99 999999\&gid $=601$

Organización de Estados Iberoamericanos para la Educación la Ciencia y la Cultura - OEI. 2003. Sistema Educativo Nacional de Portugal. Consult. 5 Janeiro 2012, disponível em http://www.oei.es/quipu/portugal/historia.pdf

PACHECO, J. Currículo: teoria e práxis. Porto Editora: Porto, 2001.

PERDIGÃO, T. Tesouros do artesanato Português. Lisboa: Verbo, 2001.

PINTO, A.; Meireles, F.; Cambotas, M. História da arte ocidental e portuguesa das origens ao final do século XX. Porto: Porto Editora, 2001.

ROLDÃO, M. C. Gestão do currículo e avaliação de competências. Barcarena: Editorial Presença, 2003.

SANTOS, M. O Artesanato no Concelho da Moita. $2^{a}$ Ed. Moita: Câmara Municipal da Moita - Divisão de Acção Cultural, 1998. Consult. 7 Dezembro 2011, disponível em http://www.cm- moita.pt/NR/rdonlyres/D52C78DF-87C4-4928- A1936876BA7243C4/5280/artesanato.pdf

SÉGUY, G. Promover o Homem. In Niza, S. (Dir.). A escola e a sociedade. Lisboa: Editorial Estampa, 1977.

SILVA, A. S. Novos artesãos portugueses: quem são, o que fazem? In Feira Internacional de Artesanato - FIL. As idades do futuro. Lisboa: IEFP, 2000.

TEODORO, A. O sistema educativo - situação e perspectivas. Lisboa: Livros Horizonte, 1982.

UNESCO. Convenção para a salvaguarda do património cultural imaterial. Paris: Comissão Nacional da Unesco. 2003. Consult. 3 Janeiro 2012, disponível em http://unesdoc.unesco.org/images/0013/001325/132540por.pdf 
VIEIRA, E. F. e Vieira, M. M. F. A dialética da pós-modernidade: a sociedade em transformação. Rio de Janeiro: Editora FGV, 2004. Consult. 15 Janeiro 2012, disponível em http://books.google.pt/books?id=ro0FTEEewxgC\&pg=PA78\&dq=evolu\%C3\%A7\%C3\%A3 $0+$ da + sociedade\&hl $=$ ptPT\&sa $=X \& e i=8 w I c T L F I c L h Q f o y 53 W D A \& v e d=0 C E s Q 6 A E w B g \# v=0$ nepage $\& q=$ evolu $\%$ C3\%A7\%C3\%A3o\%20da\%0sociedade $\& f=$ false

WCC - Conselho mundial de Artesanato. Declaração de Jacarta sobre o papel do artesanato no processo de desenvolvimento. Indonésia - Jacarta. 1985. Consult. 12

http://nandeva.org/home new2/pesquisa/declaracao viena.pdf

Ana Carina Guerreiro Lopes

Universidade de Lisboa

Recebido em: 23/09/2013

Aprovado em: 15/10/2013 